\title{
THE ELECTRORETINOGRAM OF THE SODIUM GLUTAMATE TREATED ALBINO RAT: ITS CHARACTERISTICS AND COMPARISON WITH THOSE OF THE UNTREATED RAT
}

\author{
Stanley BUCKSER \\ Southern College of Optometry, 1246 Union Avenue, \\ Memphis Tennessee 38104
}

\begin{abstract}
This paper describes ERG's obtained from all rod retinas containing essentially only a-waves. Albino rats, treated with sodium glutamate, were used. The fractionated ERG's obtained from dark adapted rats were in response to stimuli of varying intensity, duration, and wave length. Others were taken during the recovery from light adaptation. A small b-wave was present whenever an a-wave was absent. In the presence of an a-wave, the b-wave appeared only as a very small positive deflection at the peak of the a-wave. The a-waves obtained in these experiments are compared with those obtained from untreated albino rats. The a-wave appears unaffected by the sodium glutamate treatment.
\end{abstract}

\section{INTRODUCTION}

It has been reported $^{1)}$ that treating suckling white mice with sodium 1-glutamate causes degeneration of the ganglion cell layer and the inability of the retinal inner nuclear layer to form, leaving the receptor cells intact. Three months after the treatment of white mice and albino rats with sodium glutamate, only a ragged layer of bipolar cells, usually two cells thick, is present in the retinas ${ }^{2,3}$. The electroretinogram of these animals exhibited a characteristic loss of the b-wave, while preserving the a-wave. The effect of the sodium glutamate treatment upon the a-wave has not been reported.

Although temporary abolition of the $b$-wave by various techniques has been reported, treatment with sodium glutamate is still the only method known of producing animals that are healthy and normally functioning whose ERG under normal conditions does not appear to have any trace of a b-wave.

Received for publication November 8, 1968 
Because the gross ERG represents a summation of electrical activity from different layers within the retina, any attempt to relate the ERG to the activity of its separate sources will be hindered because of the mixing of the responses arising from the different sources. By examining ERG's from animals whose retinas contain only one type of receptor, e.g. all rods, and fractionating out most of the other retinal cells by treatment with sodium glutamate, some of the complexity of the ERG caused by the contributions of the different cells can be removed. This would provide information concerning the characteristics of one wave arising from the receptor cells without the complications caused by contributions from other cells. The characteristics of the a-wave, without the complexities caused by its summation with the b-wave, can be studied.

Although indications of a small number of cones, or conelike rods, have been reported in the albino rat retina, it is considered to consist of essentially all rods ${ }^{4,5)}$.

In this paper the characteristics of the glutamate treated albino rat ERG, containing essentially only an a-wave, are analyzed as a function of accurately defined stimulus intensity, duration, and wave length. The recovery of the fractionated ERG a-wave properties after the eye is exposed to a preadapting light is also determined. The properties of the glutamate treated rat ERG are compared with those previously reported on the untreated rat for equivalent stimuli ${ }^{6,7)}$.

The interpretation of these data, and a model describing the interactions between the a-wave and the various sub-waves of the b-wave, and how the glutamate treatment affects these interactions will be reported in the next paper in this series.

\section{METHODS}

Albino rats (Sprague-Dawley strain) were injected intraperitoneally with a single daily dose of sodium glutamate beginning on the second day of life for fourteen days using the dosages described by Potts, Modrell and Kingsbury.2) The rats were used for ERG studies at about three months of age. The average weight was about 250 grams.

The rats were dark adapted for 16-20 hours prior to use. The animals were immobilized with $0.2 \mathrm{cc}$ curare (Introcostrin or Tubocurarine Hydrochloride, E. R. Squibb and Company, New York) injected intramuscularly, and then maintained on a respirator. The cornea was anesthetized with two drops of Pontocaine (Winthop Laboratories, New York), and the pupil was dilated with two drops of $1.0 \%$ atropine. The eyelids were sutured so that the eye remained open. A saline moistened wick electrode in series with a freshly chlorided silver wire served as the active electrode and was placed at the edge of the pupil. A stainless steel electrode was inserted under the skin approximately one $\mathrm{cm}$. from the eye. The ear was connected to ground. The entire preparatory procedure was performed in dim red light, and an hour of complete dark adaptation followed the preparatory procedure prior to experimentation. 
The electrocardiogram was monitored throughout the experiment, and a mimimum pulse rate of 360 per minute was necessary for a satisfactory experiment.

Most of the experiments were performed with an A.C. amplification system having high and low frequency cut off's at 1000 and 0.06 cycles per second, respectively. The preparation was in a shielded lighttight room. The ERG signal went from the eye to a cathode follower to an A.C. preamplifier (Model P 6, Grass Instrument Company, Quincy, Massachusetts). The signal was relayed to a high gain A.C. preamplifier oscilloscope plug-in unit (Type E, Tektronix, Oregon) and displayed on one channel of a dual beam oscilloscope (Model 551, Tektronix). The display was photographed with a $35 \mathrm{~mm}$. oscilloscope camera (Model C4, Grass Instrument Company). The data were displayed in a microfilm reader (Model MPE, Eastman Kodak Company, Rochester, New York) to facilitate measurement. An electromagnetic shutter producing essentially a square wave light pulse was used8). White light having a peak wave length at $6500 \AA$ was used for the stimulus. The spectral distribution of the light source is shown elsewhere ${ }^{9}$. The stimulus was focused to a diameter of $3 \mathrm{~mm}$. at the pupil with a visual angle subtended of approximately $9^{\circ}$. Calibrated neutral density filters (Eastman Kodak Company, Rochester, New York) were placed between the light source and the eye to vary the stimulus intensity which was monitored with a photodiode (Type EA1E4, Hoffman Electronics Company, Chicago, Illinois) and displayed on the second channel of the dual trace oscilloscope plug-in unit (Type CA, Tektronix) along with time calibrations from a time marker (Type $180 \mathrm{~A}$, Tektronix).

The preparation of the animal for experimentation and the apparatus are described in greater detail elsewhere ${ }^{\text {7). }}$

The ERG's were obtained over a range of seven logarithm units and at a constant duration of $13 \mathrm{msec}$. Experiments were also performed in which the stimulus durations were varied while the stimulus intensity was kept constant.

A thermopile was used to calibrate a set of interference filters so that with appropriate neutral density filters and equal quantity of light energy reached the thermopile through each interference filter. Stimuli having equal energy and duration of $1,644 \mathrm{ergs}$ and $13 \mathrm{msec}$, respectively, but different wave lengths were presented to the eye and the ERG was recorded. The average half-weight band width of the interference filters was $50 \AA$.

The time between stimuli varied from two minutes at the lowest intensities and durations to 15 minutes at the highest intensities and durations to keep the state of dark adaptation constant. This constant state of dark adaptation was tested by recording several ERG's in response to the same stimulus. When the ERG's were identical, it was concluded that the state of dark adaptation did not vary.

The methods used in experiments of recovery from light adaptations are described elsewhere ${ }^{10)}$. The intensity of the adapting light in these experiments was $1.59 \times 10^{5}$ ergs/sec. The light was on for 10 seconds. The ERG stimulus intensity in these experiments was $8.42 \times 10^{4} \mathrm{ergs} / \mathrm{sec}$ for a duration of $13 \mathrm{msec}$.

\section{RESULTS}

Some of the measurable components of the ERG are shown in FIG. 1.

A-latency is the time (in $\mathrm{msec}$.) between the onset of the stimulus and the break in the case line to form the initial negative wave;

$\mathrm{E}(\mathrm{a})$ is the maximum measurable amplitude of the a-wave measured from the base line to the maximum negativity; 


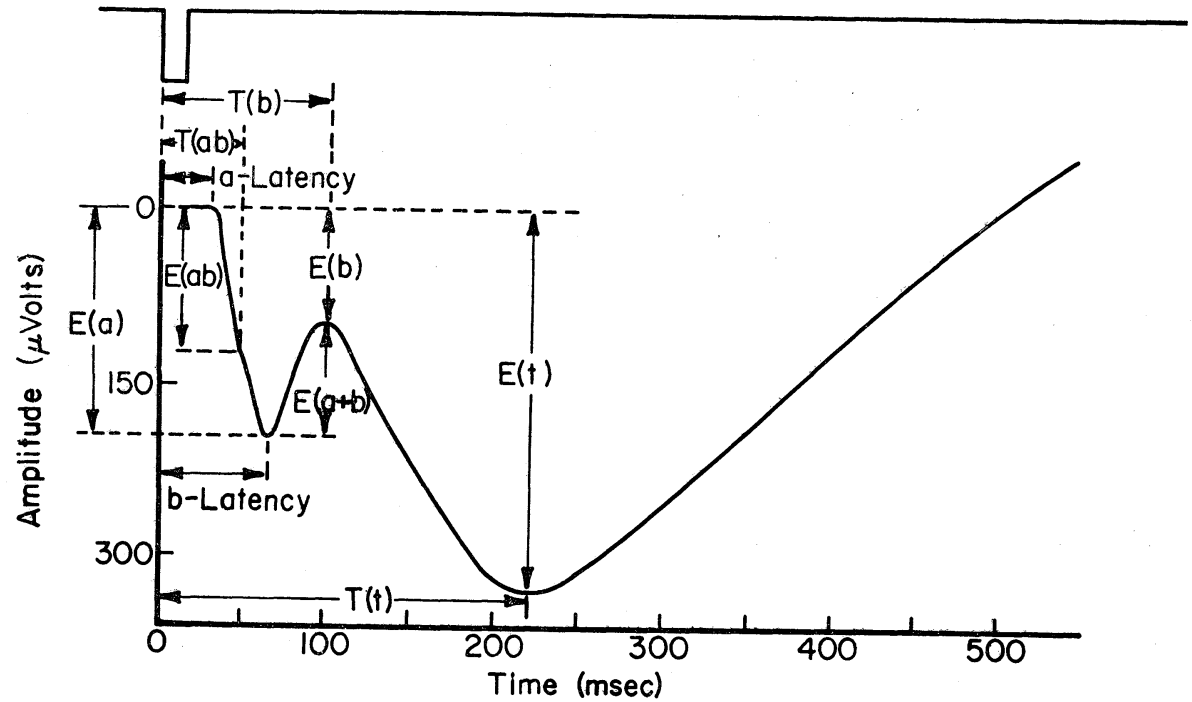

Fig. 1. Measurable ERG components. Zero time is considered to be the onset of the stimulus.

$\mathrm{E}(\mathrm{b})$ and $\mathrm{E}(\mathrm{a}+\mathrm{b})$ are the maximum amplitudes of the $\mathrm{b}$-wave measured from the base line to the uppermost point of the positive deflection and from the trough of the a-wave to the most positive point on the b-wave, respectively ;

$\mathrm{E}(\mathrm{t})$ is the maximum amplitude of the negative wave following the $\mathrm{b}$ wave ;

$T(a), T(b)$ and $T(t)$ are the peak latencies (the times after the onset of the stimulus at which the respective amplitudes were measured) of the awave, the $b$-wave, and the negative wave following the $b$-wave.

B-latency is the latency of the b-wave when there is no a-wave present;

$\mathrm{T}(\mathrm{a})$ is approximately equal to b-latency when an a-wave is present;

$\mathrm{E}(\mathrm{ab})$ is the amplitude of the break in the slope of the a-wave.

$\mathrm{T}(\mathrm{ab})$ is the time after the onset of the stimulus when the break in the slope occurs.

The reproducibility of the results is discussed elsewhere ${ }^{8,11}$. When rats are subjected to graded stimuli, the results are reproducible. The absolute amplitude of the responses varies from animal to animal. A response to the same stimulus by different rats may have a $100 \%$ variation in the amplitude for these animals. The absolute amplitude of the ERG waves is a function of the positioning of the stimulus and electrode upon the eye, the type and condition of the electrode, and animal's condition, as well as the state of adaptation of the animal and the stimulus. The adaptation and stimulus can be kept constant, but it is almost impossible to reproduce the other factors. Once a preparation is set up, however, the reproducibility of the results is 
very good. Responses obtained at the beginning and end of an experiment were very reproducible. The shape of the log I vs. ERG parameter functions [e.g. log I vs. E(a)] was the same for all 22 intensity studies. Although the absolute value of each entire function differed from animal to animal, the relationship of the response from one stimulus to another within a series [e.g. $\mathrm{E}(\mathrm{a})$ at one $\log \mathrm{I}$ to $\mathrm{E}(\mathrm{a})$ at some other $\log \mathrm{I}$ ] as well as one entire parameter function to another [e.g. $\mathrm{E}(\mathrm{a})$ and $\mathrm{E}(\mathrm{b})$ vs. $\log I]$ was constant, and independent of the animal, the electrode or the stimulus positioning.
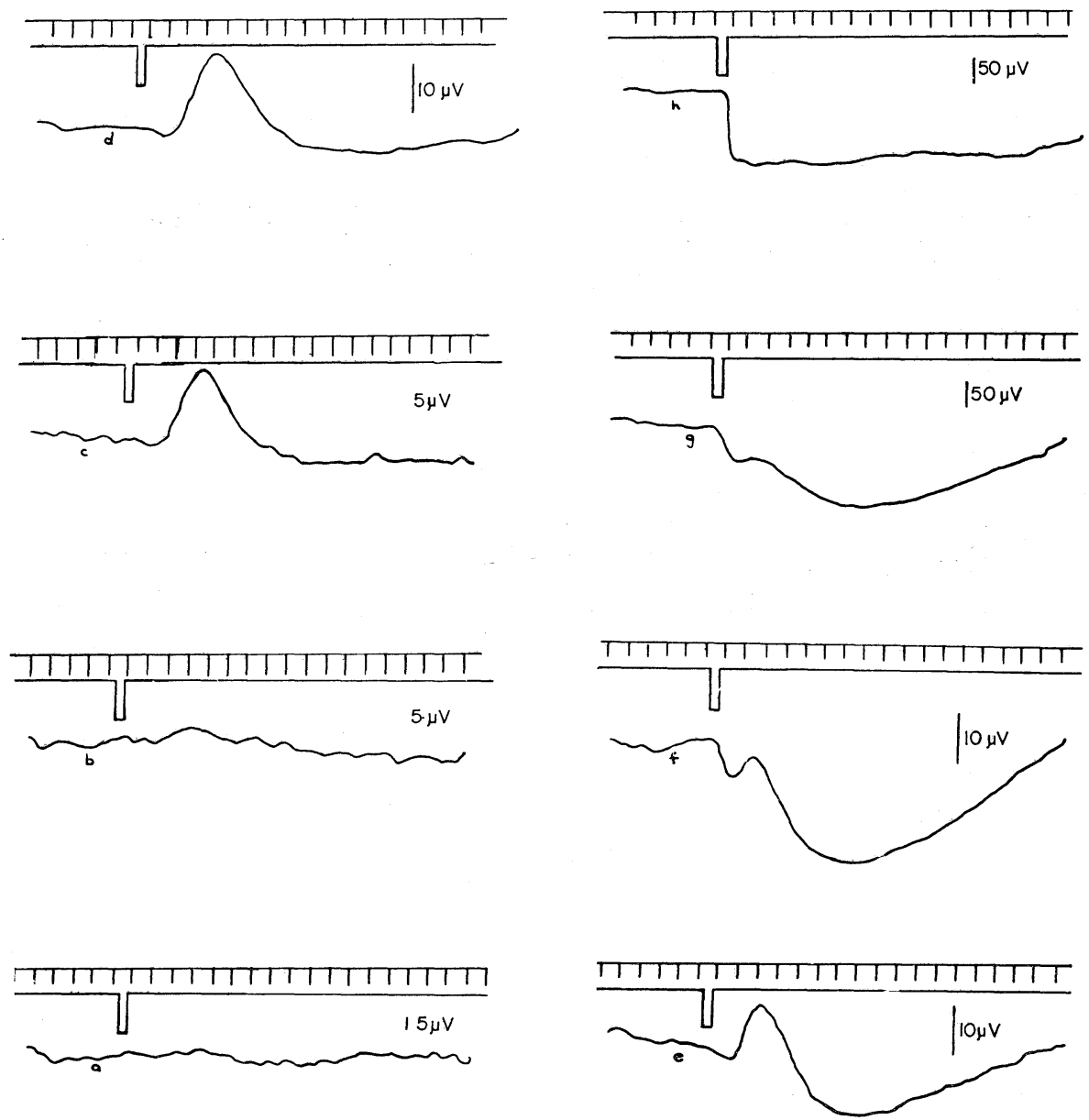

FIG. 2. Effect of stimulus intensity upon the ERG under dark adapted conditions. These ERG's are tracings obtained from part of a series obtained from one animal in one experiment. The time markers are every $50 \mathrm{msec}$. The stimulus is $13 \mathrm{msec}$. Voltage calibrations are to the right of each ERG. Note that the calibrations are not constant for all the ERG's. The stimulus intensities are a. $2.24 \mathrm{erg} /$ sec, b. $12.4 \mathrm{erg} / \mathrm{sec}$, c. $73.8 \mathrm{erg} / \mathrm{sec}$, d. $2.41 \times 10^{2} \mathrm{erg} / \mathrm{sec}, 2.07 \times \mathrm{i} 0^{3} \mathrm{erg} / \mathrm{sec}, 2.69 \times 10^{3}$ $\mathrm{erg} / \mathrm{sec}, 6.96 \times 10^{3} \mathrm{erg} / \mathrm{sec}, 3.74 \times 10^{5} \mathrm{erg} / \mathrm{sec}$. 
Tracings of several ERG's selected fromla series obtained from one dark adapted, glutamate treated rat in response to stimuli of increasing intensity are shown in Fig. 2. This series is similar to all the others, although the absolute amplitude of each series may vary. The order of the stimulus intensities was chosen randomly. At very low stimulus intensities there is no detectable response, other than electrical noise. The first response that is detected as a positive deflection, as seen at $b$. The negative wave, isolated by ARDEN and BROWN ${ }^{12)}$ and BUCKSER ${ }^{13)}$ at stimulus intensities below the bwave threshold in the normal albino rat, was not observed for the glutamate treated rats. A negative tail following the b-wave having an amplitude of $7 \mu$ volts is observed in response to a higher stimulus intensity at c, although there is still no detectable a-wave. This was also observed with a D.C. coupled amplification system. The positive deflection, or b-wave, increases in amplitude with increasing stimulus intensity and reaches a maximum amplitude at the stimulus intensity at which the a-wave is first observed, d. A break in the rising edge of the $b$-wave at about half its maximum amplitude and a change in the slope of the descending edge near the maximum are evident in this ERG. The amplitude of the negative tail wave is greater than that of the a-wave. With increasing stimulus intensity the a-wave and tail wave amplitudes increase, whereas the b-wave amplitude decreases. The peak of the a-wave is much broader than those obtained from non-treated rats in response to the same stimuli. At $f$, the positive deflection that occurs after the a-wave does not reach the base line. At $\mathrm{g}$, the positive deflection is observed as a small broad blip following the a-wave that is not even evident at $h$. The a-wave has several breaks in the slope before reaching its peak. These breaks become more evident as the stimulus intensity increases and the $b$-wave amplitude decreases. It is difficult to determine whether the peak of the a-wave in the ERG shown at $h$ is reached after the onset of the stimulus, or after the small blip following the initial negativity. The negative potential reached after the blip is slightly greater than before it. The

TABLE 1.

\begin{tabular}{l|c|c|c|c|c|c|c|c|c}
\hline Fig. & $\begin{array}{c}\text { Intensity } \\
(\text { Ergs/sec })\end{array}$ & $\begin{array}{c}\mathrm{E}(\mathrm{b}) \\
(\mu \mathrm{V})\end{array}$ & $\begin{array}{c}\mathrm{T}(\mathrm{b}) \\
(\mathrm{msec})\end{array}$ & $\begin{array}{c}\mathrm{b}-\mathrm{T}(\mathrm{at}) \\
(\mathrm{msec})\end{array}$ & $\begin{array}{c}\mathrm{E}(\mathrm{t}) \\
(\mu \mathrm{V})\end{array}$ & $\begin{array}{c}\mathrm{T}(\mathrm{t}) \\
(\mathrm{msec})\end{array}$ & $\begin{array}{c}\mathrm{E}(\mathrm{a}+\mathrm{b}) \\
(\mu \mathrm{V})\end{array}$ & $\begin{array}{c}\mathrm{E}(\mathrm{a}) \\
(\mu \mathrm{V})\end{array}$ & $\begin{array}{c}\text { a-lat. } \\
(\mathrm{msec})\end{array}$ \\
\hline 1-a & 2.24 & & & & & & & & \\
$1-\mathrm{b}$ & 12.4 & 8.8 & 200 & 100 & & & 8.8 & & \\
$1-\mathrm{c}$ & 73.7 & 44.3 & 195 & 75 & 7 & & 44.3 & & \\
$1-\mathrm{d}$ & $2.41 \times 10^{2}$ & 76.6 & 160 & 62 & 29.3 & 500 & 83.4 & 6.8 & 30 \\
$1-\mathrm{e}$ & $2.07 \times 10^{3}$ & 43.3 & 138 & 60 & 53.2 & 350 & 56.4 & 13.1 & 30 \\
$1-\mathrm{f}$ & $2.69 \times 10^{3}$ & -15.3 & 104 & 63 & 100 & 320 & 25.2 & 40.6 & 20 \\
$1-\mathrm{g}$ & $5.96 \times 10^{3}$ & -59.8 & 100 & 65 & 150 & 350 & 8.5 & 68.4 & 20 \\
$1-\mathrm{h}$ & $3.74 \times 10^{5}$ & & & 79 & & & & 143.6 & 10 \\
\hline
\end{tabular}


measurable parameters obtained from this series are summarized in TABLE I.

The a-wave amplitude vs. log I data obtained from three glutamate treat-
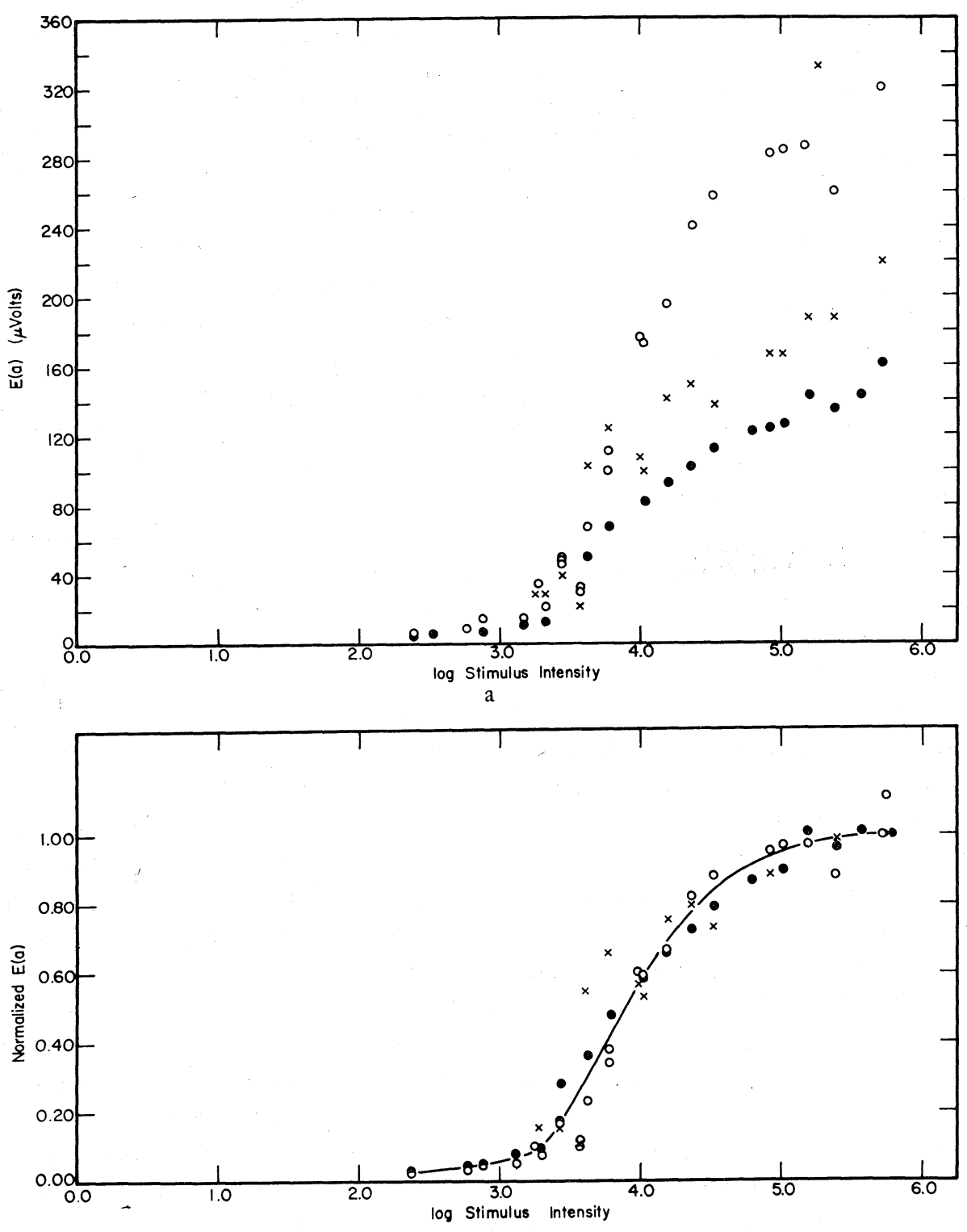

b

FIg. 3. The effect of stimulus intensity upon the a-wave. (a) E(a) vs. $\log I$. Data obtained from the three experiments showing the widest scatter are shown. (b) Normalized E(a) vs. $\log$ I. These are the same data shown in (a). 
ed rats are plotted in FIG. 3a. These data are normalized by dividing all the points obtained in each experiment by the amplitude reached at the highest stimulus intensity of the light source. The results are shown in FIG. 3b.

The ERG parameters were measured as a function of stimulus intensity for 12 intensity experiments. A representative group of parameters obtained from one experiment are shown in FIG. 4. The a-wave in FIG. 4a is detected at $\log \mathrm{I}$ of 2.75 . The $\mathrm{E}(\mathrm{a})$ vs. $\log \mathrm{I}$ curve consists of three regions. In the first region $\mathrm{E}(\mathrm{a})$ increases slowly with $\log \mathrm{I}$ over one $\log$ unit of intensity. The a-wave amplitude increases 10-12 times over the next $1.5 \log$ I units in the second region. The third region consists of the a-wave amplitude increasing slowly with increasing log I. E (a) increases only by $20 \%$ in this region.

The positive deflection, or b-wave, in FIG. 4a is clearly observable at log I of 1.5. $E(b)$ increases with increasing $\log I$ of 2.9 , an intensity slightly higher than the observed a-wave threshold. $E(b)$ decreases with increasing intensity until it does not reach the base line from the trough of the a-wave, and finally is barely observable at the peak of the a-wave. At the higher stimulus intensities $E(b)$ has a negative value. The $E(a+b)$ vs. $\log$ I curve has the same shape as the $\mathrm{E}(\mathrm{b})$ vs. $\log$ I curve except that the former has positive amplitudes and levels off at approximately the intensity at which the second region of the $\mathrm{E}(\mathrm{a})$ vs. $\log$ I curve begins. The tail wave is detected at a $\log$ I of 1.75 , a threshold slightly higher than that of the b-wave and one $\log I$ unit lower than that of the a-wave. $E(t)$ increases with intensity for $2.5 \mathrm{log}$ I units and then remains constant. The negative tail wave amplitude is always larger than the a-wave amplitude. At high stimulus intensities where there is only a very small b-wave, the difference in amplitude between the a-wave and tail wave is very small.

In FIG. 4b, the a-wave latency decreases from approximately $40 \mathrm{msec}$. at the a-wave threshold to $10 \mathrm{msec}$. at the higher intensities. $\mathrm{T}(\mathrm{a})$ remains constant with increasing $\log I$ at about $61 \mathrm{msec}$. until $\log \mathrm{I}$ of 4.3 where it decreases about $12 \mathrm{msec}$., followed by an increase to $78 \mathrm{msec}$. $\mathrm{T}(\mathrm{b})$ is constant with increasing stimulus intensity at approximately $180 \mathrm{msec}$., until log I equals 2.75 . $T(\mathrm{~b})$ then decreases rapidly with increasing log I to approximately $90 \mathrm{msec}$. at $\log \mathrm{I}$ of 3.75 . $\mathrm{T}(\mathrm{b})$ remains constant with increasing intensity for almost $0.75 \mathrm{log}$ I units, and then increases to about $130 \mathrm{msec}$. The log I's of 2.75 and 3.75 are the intensities at which the a-wave first appears and at which the rapid increase in the a-wave amplitude begins, respectively. The leveling off in the $T(b)$ vs. $\log$ I curve occurs at the same intensity as that at which the third region in the $\mathrm{E}(\mathrm{a})$ vs. $\log \mathrm{I}$ curve starts. Since the peak of the $b$-wave is broad, the measurements are more difficult to make and the scatter in the data is greater. The data obtained from two intensity experiments are shown for $\mathrm{E}(\mathrm{b})$ vs. $\log \mathrm{I}$. These curves are similar to those obtained from other experiments. 


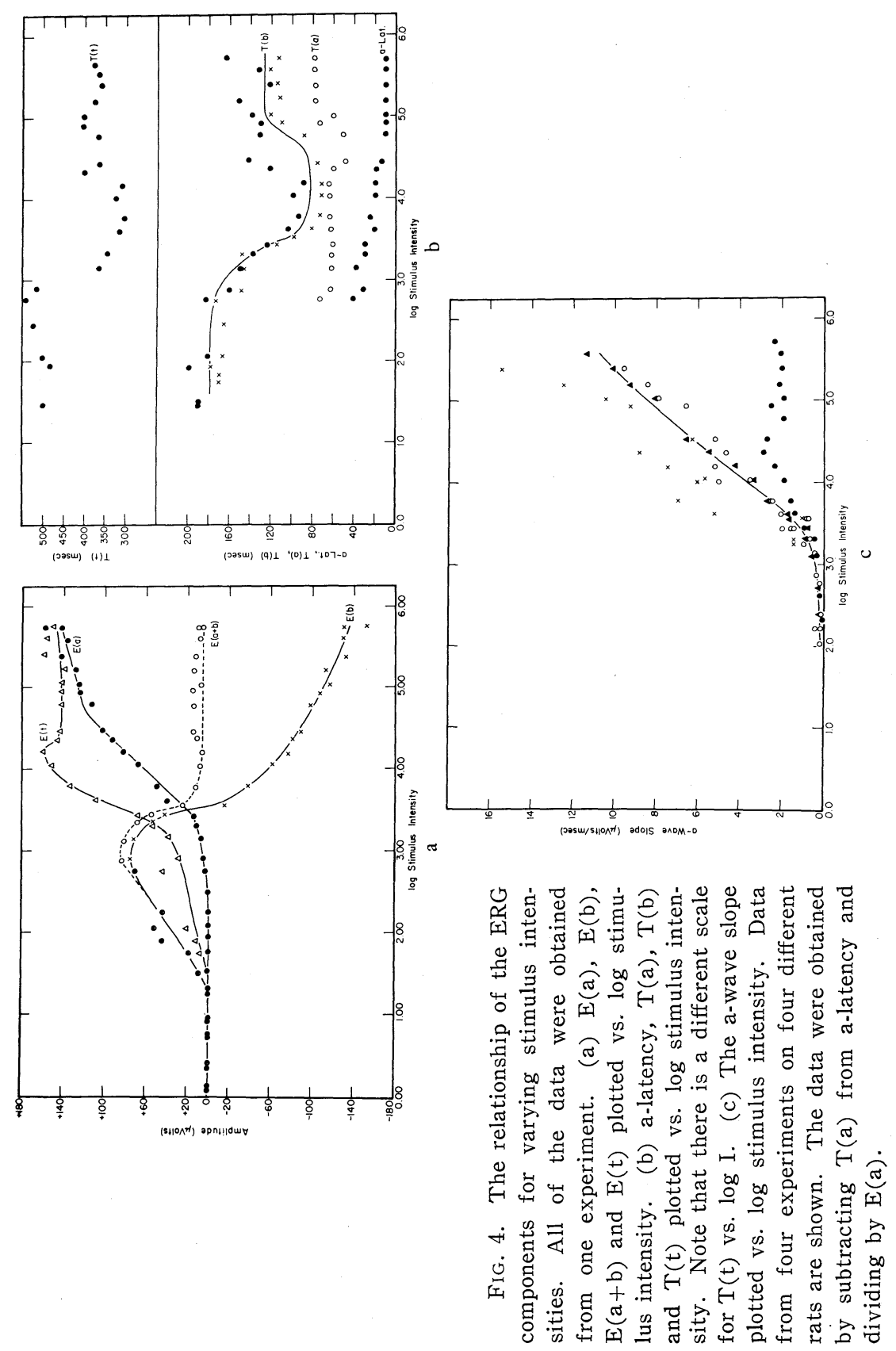


$T(t)$ is the most difficult measurement to make because there is a rounding of the amplitude, rather than a sharp change in polarity at the maximum amplitude of the tail wave. The measurement is therefore not as precise as the preceding ones. $T(t)$ remains constant at about $500 \mathrm{msec}$. with increasing stimulus intensity until $\log$ I equals 3.9 where it decreases to about 310 msec. The $\mathrm{T}(\mathrm{t})$ vs. $\log$ I curve remains at $310 \mathrm{msec}$. for almost $0.75 \mathrm{log} \mathrm{I}$ units followed by an increase to about $375 \mathrm{msec}$. $T(t)$ becomes shorter at approximately the same intensity at which the a-wave is experimentally detected.

The a-wave slope was calculated by dividing the a-wave amplitude by the difference between the a-wave peak latency and the a-wave latency. Because of the rounded nature of the a-wave peak in glutamate treated rats, the peak latency data are not precise, thus creating imprecise slope calculations. The a-wave slope vs. log I curves obtained from four glutamate treated rats are shown in Fig. 4c.

A series of ERG's obtained from one dark adapted rat in response to stimuli of equal energy, but differing wave length are shown in FIG. 5a. From 5-13, the a-wave peak is taken as the first break in the negative wave. The tail wave peak is the point at which the maximum negativity occurs. $\mathrm{E}(\mathrm{b})$ for these ERG's is a negative quantity and $\mathrm{E}(\mathrm{a}+\mathrm{b})$ is very small and only begins to increase as the a-wave amplitude decreases.

The a-wave amplitude vs. wave length data obtained from three glutamate rats are shown plotted in FIG. 5b. These data are normalized by dividing all the points obtained in each experiment by the amplitude obtained at $5070 \AA$, the wave length at which the maximum a-wave amplitude occurred. The results are shown in Fig. 5c. A small secondary maximum in the $\mathrm{E}(\mathrm{a})$ vs. wave length curve appears at about $4670 \AA$ in all the wave length experiments performed.

All of the ERG parameters obtained from one experiment are plotted vs. wave length in FIG. 6 to show the relationships between the parameters. The a-wave amplitude increases with wave length to a maximum at about $5070 \AA$, and then decreases with increasing wave length. The a-wave is not observed at wave lengths greater than $6200 \AA$. Because of the rounded nature of the negative tail wave, it is impossible to determine precisely where its peak occurs. The negative tail wave amplitude is about twice as great as $\mathrm{E}(\mathrm{a})$. It increases with wave length to a plateau and then decreases with increasing wave length. $E(t)$ starts to decrease at about $6000 \AA$, after $\mathrm{E}$ (a) starts decreasing wave length, and is observable at much higher wave lengths.

$\mathrm{E}(\mathrm{b})$ and $\mathrm{E}(\mathrm{a}+\mathrm{b})$ are plotted vs. wave length in FIG. 5b. $\mathrm{E}(\mathrm{b})$ decreases to a minimum at approximately $5020 \AA$ and then increases to a maximum at about $6400 \AA$. The data obtained from the three experiments having the 

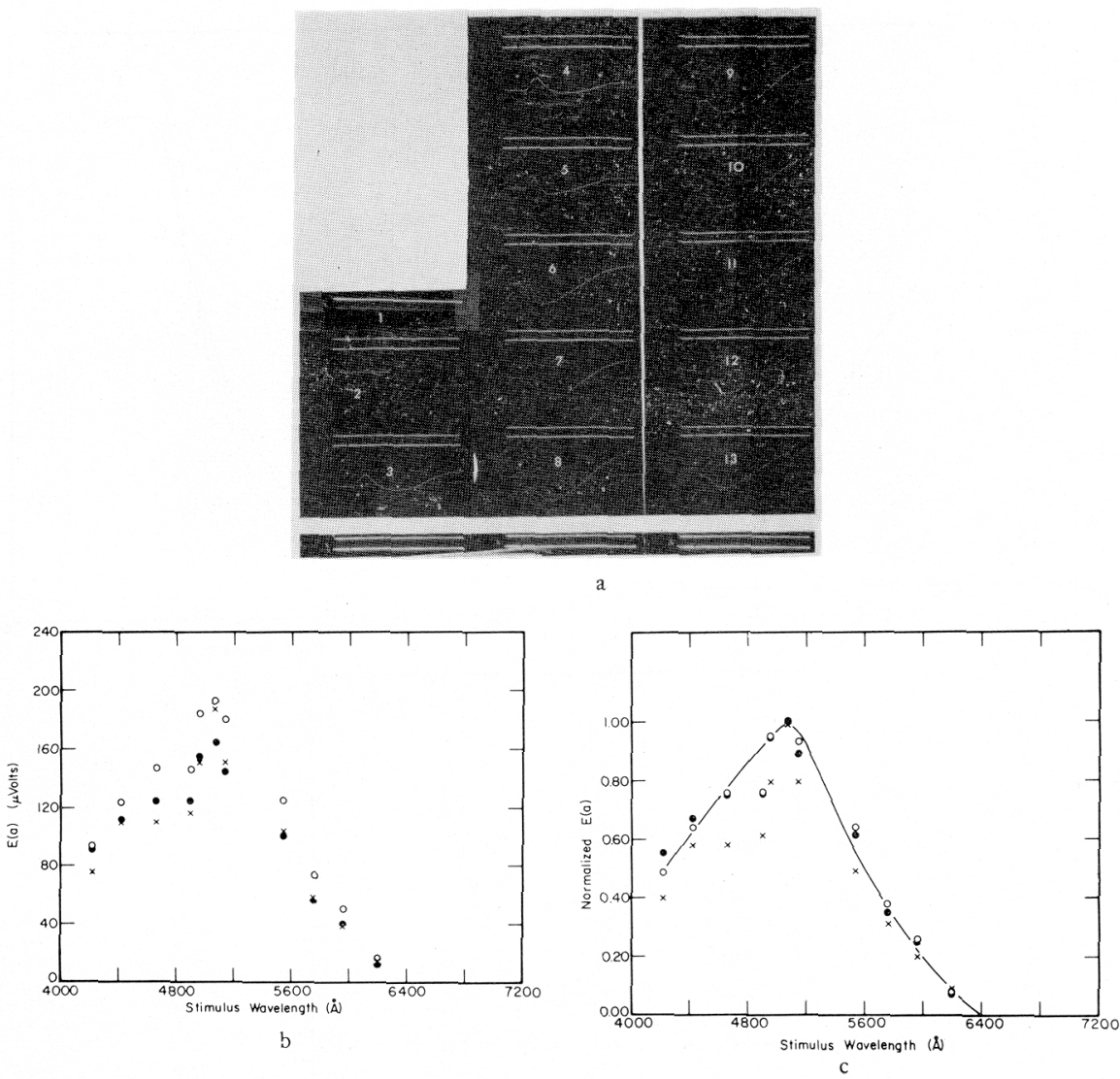

FIG. 5. The effect of stimulus wave length upon the a-wave. (a). ERG's obtained in response to stimuli of varying wave length but equal energy and duration. The time calibrations at 1 are every $50 \mathrm{msec}$. The voltage calibration at 2 is 500 uVolts. The wave lengths are: 3. $6772 \AA, 4.6595 \AA, 5.6206 \AA, 6.5960 \AA$, 7. 576 c $\AA, 8.5540 \AA, 9.5135 \AA, 10.4903 \AA, 11.4908 \AA, 12.4665 \AA, 13.4425 \AA$. (b) $\mathrm{E}$ (a) plotted vs. wave length. Data are shown for three experiments on different rats. (c) Normalized $\mathrm{E}$ (a) plotted vs. wave length.

greatest scatter are shown for $\mathrm{E}(\mathrm{b})$. The amplitude of the $\mathrm{b}$-wave, as measured from the trough of the a-wave to the maximum positive deflection, $\mathrm{E}(\mathrm{a}+\mathrm{b})$, is just barely observable until $4960 \AA$. In all the experiments done in this laboratory a small maximum in the $E(a+b)$ vs. wave length curve of approximately $10-20 \mu \mathrm{V}$ was observed at about $5080 \AA$. $E(a+b)$ decreased at higher wave lengths to where it was barely detectable. $E(a+b)$ starts to increase with wave length at $5760 \AA$, reaches a maximum at about $6300 \AA$, and then decreases with increasing wave length. The $b$-wave rises above the base line at wave lengths greater than $6000 \AA$. The a-wave latency is constant at $15 \mathrm{msec}$, until $5760 \AA$, then increases with wave length until it 

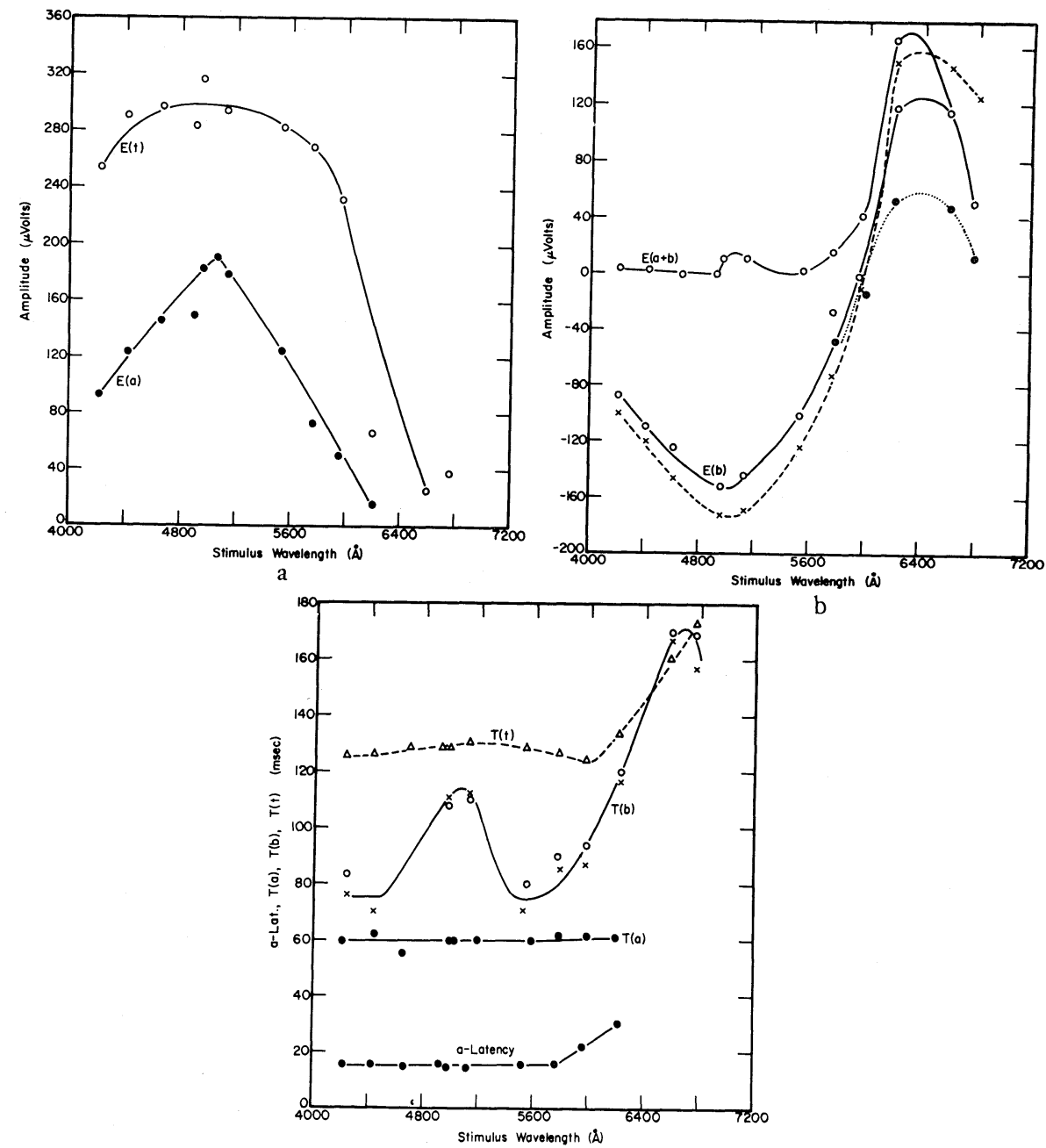

$\mathrm{C}$

FIG. 6. The relationship of the ERG components for varying stimulus wave lengths. All of the data were obtained from one experiment. (a) $E(a)$ and $E(t)$ plotted vs. wave length. (b) $\mathrm{E}(\mathrm{b})$ and $\mathrm{E}(\mathrm{a}+\mathrm{b})$ plotted vs. wave length. The slight hump in the $\mathrm{E}(\mathrm{a}+\mathrm{b})$ vs. wave length was observed in every experiment. (c) a-latency, $T(a), T(b)$ and $T(t)$ plotted vs. wave length.

cannot be measured any longer. $T(a)$ is independent of wave length and has a constant value of $60 \mathrm{msec}$. T(b) increases to a maximum at about $5000 \AA$, then decreases followed by an increase to a larger maximum at about $6600 \AA$. $\mathrm{T}(\mathrm{t})$ remains constant with increasing wave length at $128 \mathrm{msec}$, then starts to increase with increasing wave length at $6200 \AA$.

The ERG parameters are plotted vs. stimulus duration for a constant 

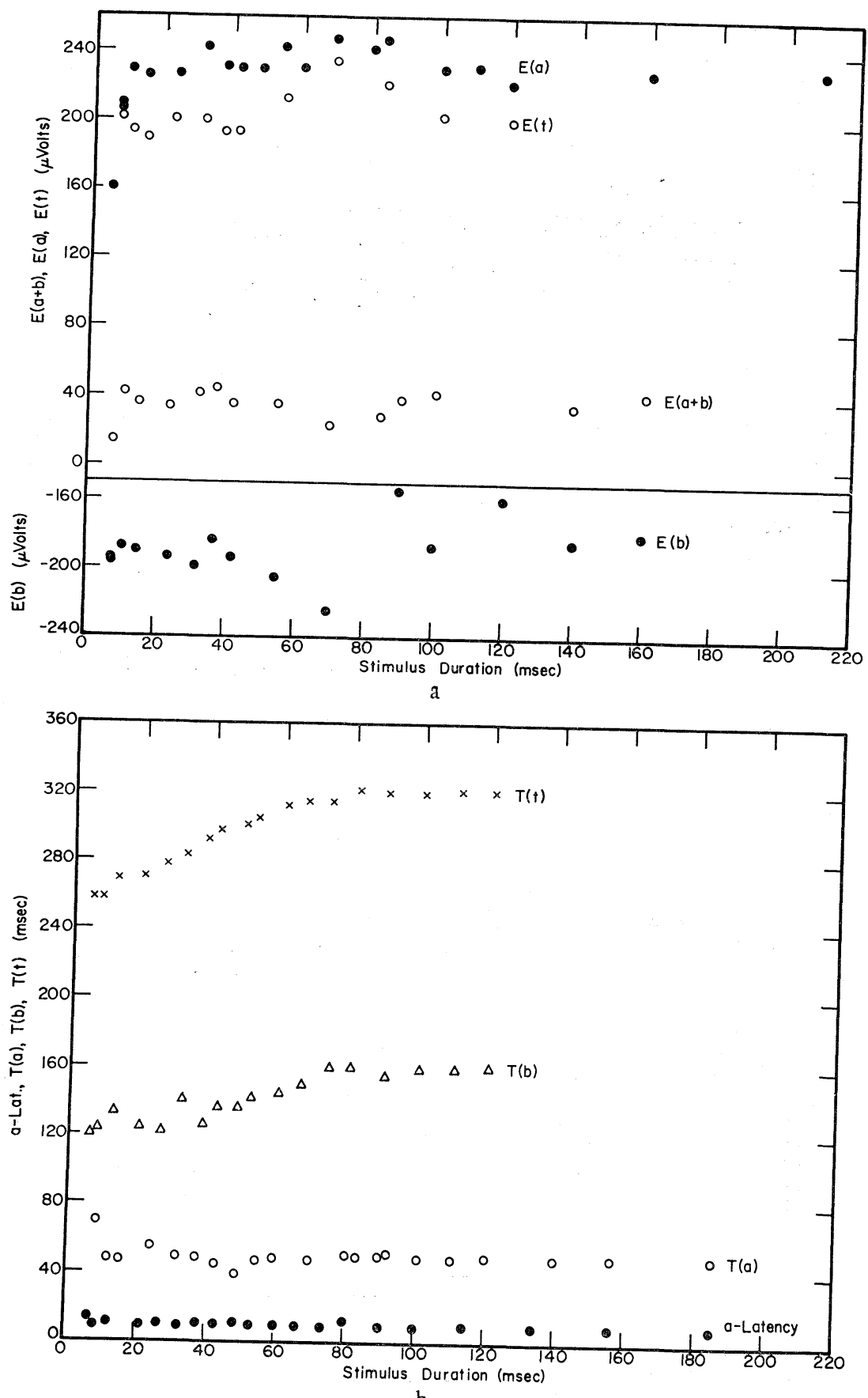

FIG. 7. The relationship of the ERG components for varying stimulus durations. The stimulus intensity is $8.42 \times 10^{4} \mathrm{erg} / \mathrm{sec}$. All the data were obtained from one experiment. (a) $\mathrm{E}(\mathrm{a}), \mathrm{E}(\mathrm{b}), \mathrm{E}(\mathrm{a}+\mathrm{b})$ and $\mathrm{E}(\mathrm{t})$ plotted vs. stimulus duration. (b) alatency, $T(a), T(b)$ and $T(t)$ plotted vs. stimulus duration. 


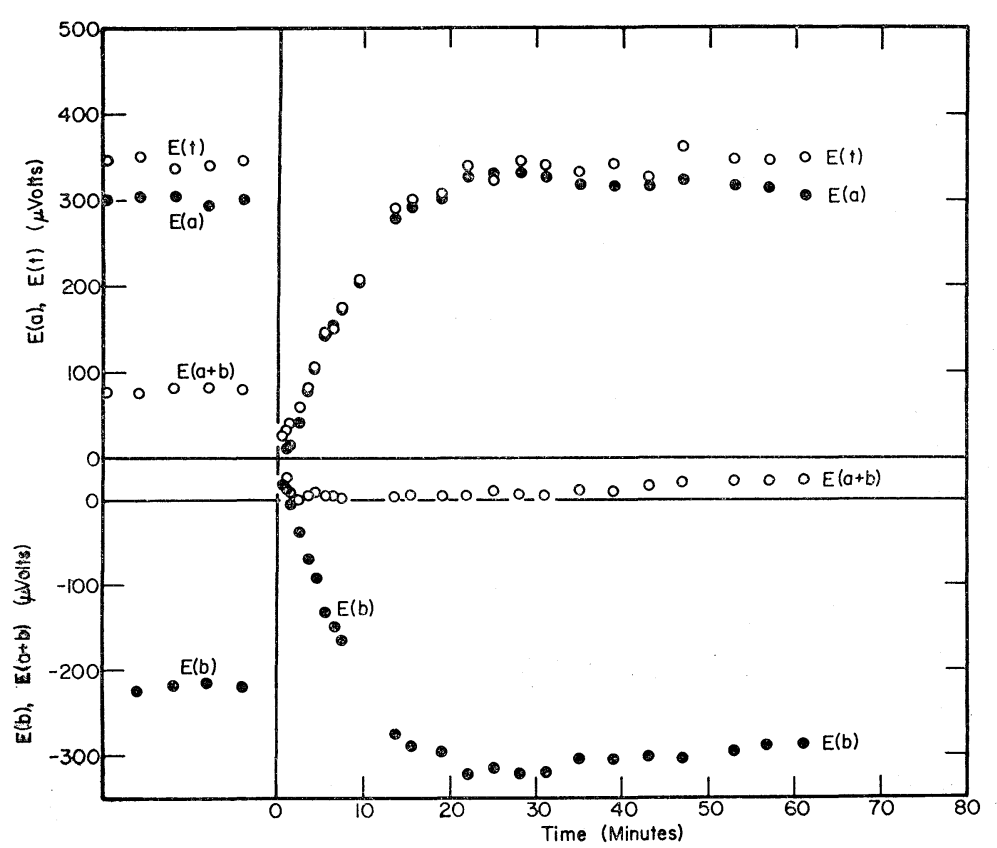

a

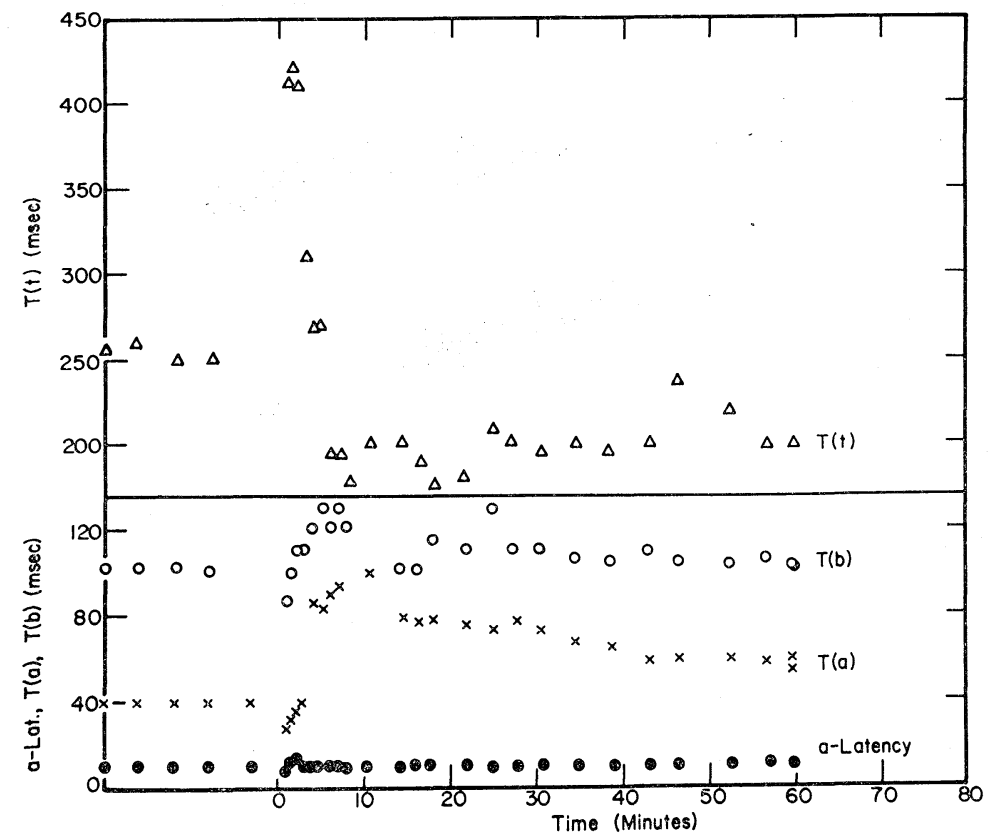

b

FIG. 8. Relationship of the ERG components during the recovery from an exposure to an adapting light. The adapting light was on for 10 seconds at an intensity of $1.59 \times 10^{5} \mathrm{erg} / \mathrm{sec}$. The ERG stimulus was $8.42 \times$ $10^{4} \mathrm{erg} / \mathrm{sec}$ for a duration of $13 \mathrm{msec}$. The pre-zero time values are from a series of responses of the dark adapted eye to the test stimulus. (a) $\mathrm{E}(\mathrm{a}), \mathrm{E}(\mathrm{b}), \mathrm{E}(\mathrm{a}+\mathrm{b})$ and $\mathrm{E}(\mathrm{t})$ plotted vs. time in the dark after the adapting light was turned off. (b) a-latency, $T(a)$ and $T(t)$ plotted vs. time in the dark. Note that there is a separate scale for $T(t)$ vs. time. 
intensity in FIG. 7. For a given intensity, E(a) increases with duration until a critical duration is reached, then remains constant with increasing duration. $T(b)$ and $T(t)$ increase with increasing duration. The remaining parameters appear independent of stimulus duration.

The ERG parameters obtained before and after the eye is exposed to an adapting light of $1.59 \times 10^{5} \mathrm{ergs} / \mathrm{sec}$ for 10 seconds are shown in Fig. 8 . The first ERG was recorded 0.5 minute after the adapting light was turned off. The b-wave appears as a small, but typical b-wave above the base line only in the first ERG recorded after the adapting light was turned off. An awave was not detected until the second ERG was recorded, 0.5 minute later. $\mathrm{E}(\mathrm{a})$, increased to $330 \mu$ Volts after 22 minutes of dark adaptation, then decreased to the pre-light adapted amplitude of $300 \mu$ Volts during the following 40 minutes. $\mathrm{E}(\mathrm{b})$ decreased from a positive amplitude of $25 \mu$ Volts in the first 0.5 minute of dark adaptation to $325 \mu$ Volts after 35 minutes. The b-wave appears as only a small blip at the peak of the a-wave. $E(b)$ increased to $-285 \mu$ Volts after 60 minutes in the dark. The pre-light adapted $\mathrm{E}(\mathrm{b})$ was $-225 \mu$ Volts. $\mathrm{E}(\mathrm{a}+\mathrm{b})$ did not recover to its pre-lighted adapted level. The negative wave following the $b$-wave was observed in the first ERG. E(t) recovered to its dark adapted value after 22 minutes and then remained constant.

The a-wave latency, after the first few minutes following light adaptation, had the same value as before the light adaptation and did not vary. T(a) and $T(b)$ decreased below the pre-light adapted values after the adapting light was turned off, then increased to maxima with time in the dark followed by a decrease. $T(b)$ decreased to the prelight adapted value whereas $\mathrm{T}$ (a) did not. $\mathrm{T}(\mathrm{t})$, however, was greatly increased after the adapting light was turned off, then decreased to considerably below the pre-light adapted value and remained constant with time in the dark.

In FIG. 9 are shown tracings of ERG's obtained in response to a constant test stimulus from a rat before, and at various times after, exposure to an adapting light. In $\mathrm{D}$ through $\mathrm{H}$ there is a break in the slope of the a-wave near the a-wave peak. The amplitude and peak latency of this break in the a-wave slope increase rapidly, and decrease slightly, respectively, with increasing time in the dark.

\section{DISCUSSION}

The purpose of this paper is to describe the ERG's obtained from all rod retinas containing only a-waves. The ERG's are compared in the following discussion with ERG's obtained from untreated animals of the same species in response to the same stimuli. Since limited knowledge of the sub-waves and their origin makes interpretations highly speculative, all opinions and 
interpretations have been omitted from this paper. Interpretation of these data and a model suggested by these data will be presented in a subsequent paper.

The characteristics of the ERC obtained from normal albino rats have been described elsewhere ${ }^{6)}$. The b-wave amplitude increases with increasing stimulus intensity until the a-wave appears. The b-wave amplitude then decreases slightly, then remains approximately constant with increasing intensity, while the a-wave amplitude increases.

These results are very much different from those obtained from the glutamate treated rats. The b-wave amplitude, smaller in absolute amplitude, also increased to a maximum with increasing stimulus intensity until the awave appeared. However, the b-wave amplitude then decreased with increasing stimulus intensity until it was barely discernible as a blip at the trough of the a-wave.

In the untreated rat the a-wave can be fractionated from the ERG by several techniques: using a light stimulus have length greater than $6200 \AA$ using a stimulus intensity below the a-wave threshold; or exposing the eye to an adapting light. In each of these methods a b-wave is always present, but a lower amplitude $b$-wave is obtained than would be obtained if the awave were present. In the first two methods the a-wave can be restored immediately by using an adequate stimulus. In the latter method the a-wave disappears and regentrates as a function of time. The recovery of the awave after partial light adaptation in the normal rat was studied by Buckser and Potts ${ }^{10)}$ and a mathematical model relating the recovery of the a-wave to the rhodopsin decomposed into opsin and all-trans retinene was presented by Buckser ${ }^{14)}$.

In the glutamate treated rat the positive deflection at the peak of the a-wave, which is the b-wave, greatly increases after treatment by any of the methods used to eliminate the a-wave. This is in contrast with the b-wave's decreasing in amplitude in the untreated rat. The b-wave appears as a small blip upon the a-wave before eliminating the a-wave, and as a small but recognizable b-wave after the a-wave is gone. A series of ERG's obtained before and after light adaption is shown in FIG. 9. The b-wave amplitude decreases slightly immediately after light adaptation but appears by itself as a positive deflection above the base line. This positive wave decreases in amplitude during the first six minutes of dark adaptation until it becomes only a very small blip on the a-wave again. The a-wave disappears temporarily after the light adaptation and recovers with time in the dark.

The largest $b$-wave amplitudes that were obtained from the glutamate treated rats ranged from 75 to $150 \mu$ Volts just before the a-wave appeared. These represent approximately $10 \%$ of those found in the normal rat, which ranged from 750 to $1800 \mu$ Volts. 


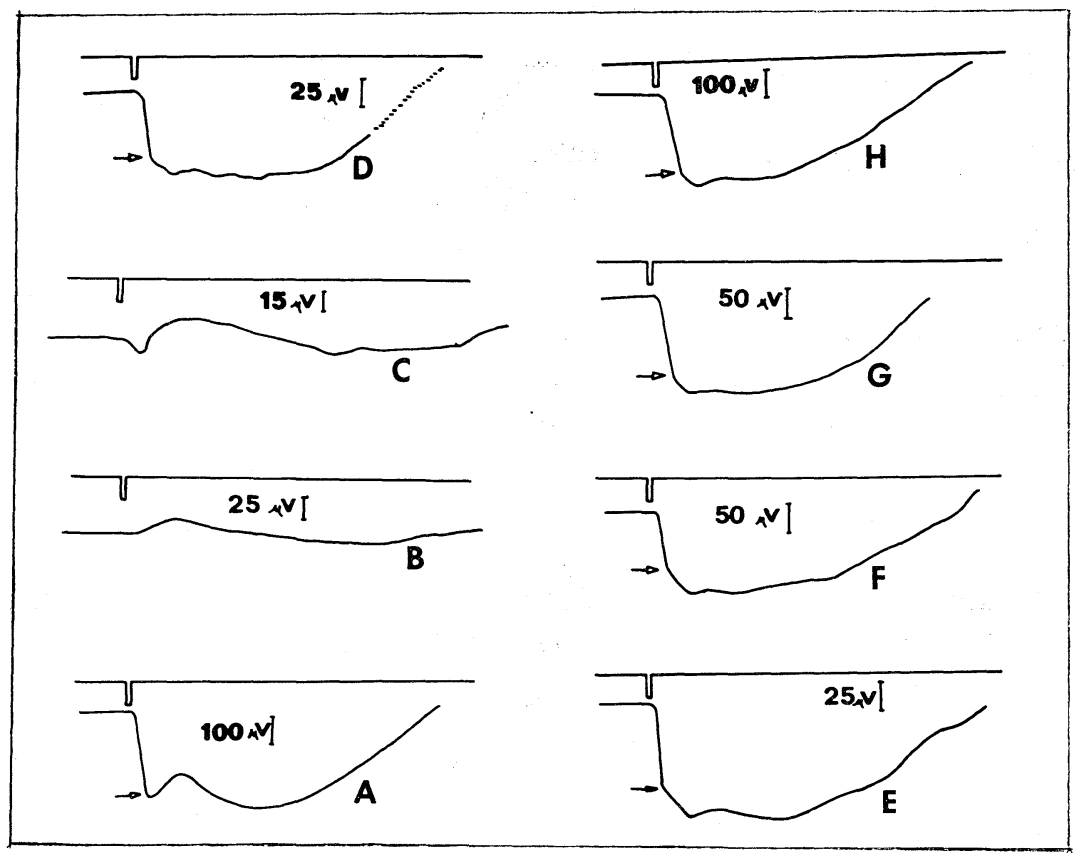

a

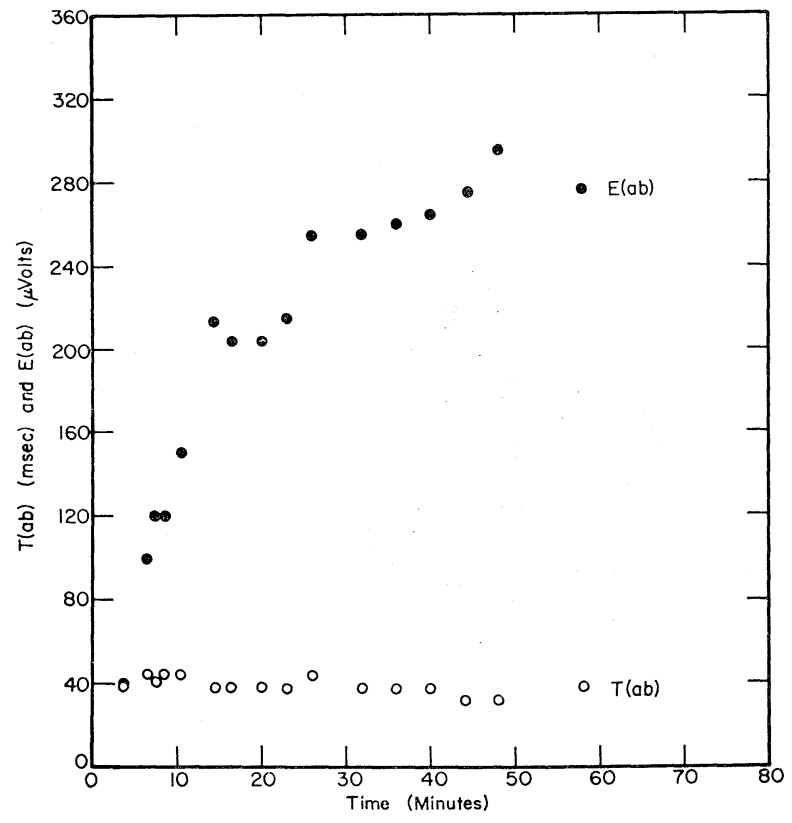

b

FIG. 9. Recovery from light adaptation. (a) Tracings obtained from a series of ERG's during the recovery from light adaptation. The arrows indicate the break in the slope of the a-wave. A. dark adapted ERG, B. 0.5, C. 1.5, D. 3.5, E. 5.5, F. 7.5, G. 11.5 and H. 15.5 minutes after the adapting light was turned off. (b) $\mathrm{E}(\mathrm{ab})$ and $\mathrm{T}(\mathrm{ab})$ plotted vs. time after the adapting light was turned off. 
In the glutamate treated rat the a-wave and $\mathrm{b}$-wave amplitudes are very small (about $15 \mu \mathrm{Volts}$ ) and large (about $170 \mu \mathrm{Volts}$ ), respectively, at $6200 \AA$. The reverse occurs at about $5100 \AA$. The a-wave and b-wave amplitudes are $190 \mu$ Volts and $10 \mu$ Volts, respectively. In the untreated rat the b-wave amplitude is greater than the a-wave amplitude at all wave lengths.

The normalized a-wave amplitude vs. log I curves obtained from three glutamate treated rats and three untreated rats (from Buckser, 1967b) are shown in Fig. 10a. They are almost identical.

The calculated a-wave slope vs. $\log$ I curves obtained from four glutamate treated rats are compared with those obtained from untreated rats in FIG. 10b. They are quite similar.

The normalized a-wave amplitude vs. wave length curve obtained from the glutamate treated rats is compared with that obtained from untreated rats $^{7)}$ and to the rhodopsin absorption curve of HUBBARD, BowndS and YosHIZAWA $^{15)}$ in FIG. 10c. The curves are very similar.

It has been suggested ${ }^{13)}$ that because of the complex interactions between the various waves of the ERG, probably the only component of the ERG unaffected by other waves is the a-wave latency. The normalized a-wave amplitude and slope vs. log stimulus intensity curves and the a-wave amplitude vs. wave length curves of the untreated and treated animals are similar. This suggests that the descending edge of the a-wave in both animals is unaffected by other waves, and that the entire a-wave is not affected by the glutamate treatment.

In both glutamate treated and normal animals, the a-wave amplitude vs. wave length curve had a large maximum at $5070 \AA$, and the b-wave curve had two maxima; a small one at $5050 \AA$ and a large one at $6200 \AA$. The small secondary maximum in the $\mathrm{E}(\mathrm{b})$ vs. $\log \mathrm{I}$ curve appears in the treated and untreated rats.

The averages of four experiments for a-latency, $T(a)$, and $T(b)$ at the stimulus intensity at which the a-wave first appears in the glutamate treated rat $(\log \mathrm{I}=2.75)$ are $30 \pm 10 \mathrm{msec}$., $61 \pm 1 \mathrm{msec}$, and $170 \pm 20 \mathrm{msec}$., respectively. The average values for the same measurements in four normal rat experiments are $27.5 \mathrm{msec}$., $40 \pm 5 \mathrm{msec}$., and $170 \pm 20 \mathrm{msec}$., respectively. The averaged data were obtained by noting the stimulus intensity at which the maximum b-wave amplitude was obtained for one typically treated rat. Using this stimulus intensity, the ERG parameters were recorded for four treated and four normal rat intensity experiments. All of the animals did not exhibit a $\mathrm{b}$-wave amplitude maximum at the same intensity, thereby creating a source of error for the average data. There is a significantly large increase of 20 msec. in $\mathrm{T}(\mathrm{a})$ of the glutamate treated animals over the untreated animals.

The time at which the break in the slope of the a-wave initiating the b-wave occurs (the arrows in FIG. 7) and the amplitude at which the break 


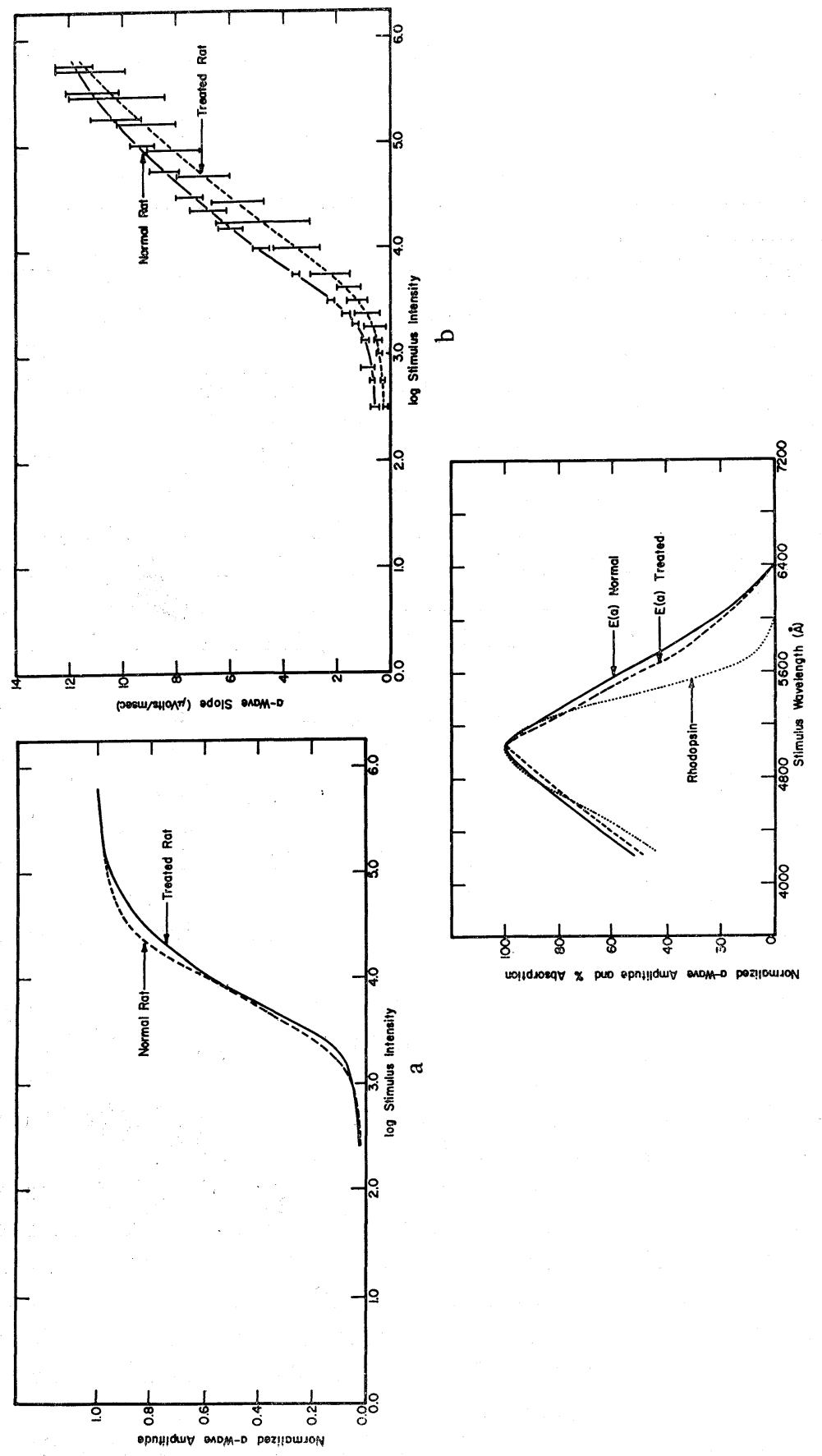

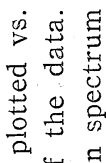

i)

节蓉

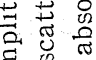

$\approx 0$.

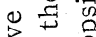

\% :

空

ت

สี เू.

ह

乙.

ฮำ

遮迸

空

空富

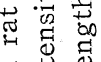

范 寻

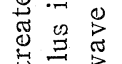

要

도를

sio

응

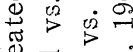

ज्ञ ठ छ

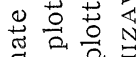

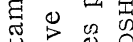

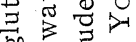

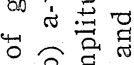

류

品市艺

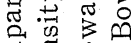

घี चี ते

ن 䒠可

울를

○寻苛出

焉兄告

을 
occurs during the recovery from light adaptation are shown in FIG. 7a and FIG. 7b for the glutamate treated rat. These figures agree with the $T(a)$ and $\mathrm{E}(\mathrm{a})$ vs. time curves obtained for the corresponding study in untreated rats. This close agreement suggests that the break in the slope of the a-wave is actually a-wave the maximum amplitude. The maximum negative potential that occurs somewhat later might be the negative wave that follows the b-wave in untreated animals.

The a-wave threshold is the same for both glutamate treated and untreated animals. The b-wave thresholds are $\log \mathrm{I}$ of 1.5 and 0.5 for glutamate treated and untreated rats, respectively. The ranges of maximum a-wave amplitudes are $150-400 \mu$ Volts and $100-300 \mu$ Volts for the glutamate treated and untreated rats, respectively.

The b-wave peak latency, $\mathrm{T}(\mathrm{b})$, in both the glutamate treated and untreated rat intensity experiments remains constant with increasing intensity up to the a-wave threshold and then decreases. In the untreated rat, $\mathrm{T}(\mathrm{b})$ continually decreases with increasing stimulus intensity, whereas in the glutamate treated rat, $T(\mathrm{~b})$ decreases to half the value it had before the a-wave appeared, then remains for about $1.25 \mathrm{log}$ I units, followed by an increase in $T(b)$ amounting to about half that of the decrease.

In the untreated albino rat $T(b)$ decreased after light adaptation and increased in the dark to an asymptotic value equal to that first found in the dark adapted animal. There was a discontinuity in the $T(b)$ vs. time in the dark curve that was caused by one of the smaller peaks in the b-wave rising in amplitude to become the dominant peak of the b-wave. BUCKSER ${ }^{6)}$ suggested that the longer latency sub-wave components of the normal rat b-wave have lower threshold sensitivities and are more sensitive to light adaptation than the shorter latency sub-waves.

In the glutamate treated rat $\mathrm{T}(\mathrm{b})$ decreased almost $20 \%$ immediately after the light adaptation, followed by a rise to a maximum that is $30 \%$ higher than the dark adapted value, and then slowly returned to the dark adapted level. There did not appear to be any discontinuity in the $T$ (b) vs. time in the dark curve, as was found in the untreated rat ${ }^{6)}$.

The a-waves in the $35 \mathrm{~mm}$. film records of ERG's obtained in response to the same stimulus from an untreated rat and a glutamate treated rat were greatly enlarged and converted to digital form. The a-waves were enlarged equally and are shown superimposed in FIG. 11a. The ERG's were obtained at different amplifications. The a-waves were corrected for their different amplifications and are shown in FIG. 11b. The waves were normalized to allow meaningful comparison. Every point in each a-wave was divided by its maximum a-wave amplitude. In FIG. 11c the normalized a-waves were positioned so that the slopes of the curves were superimposed. In FIG. 11d the normalized a-waves were positioned so that their latencies 

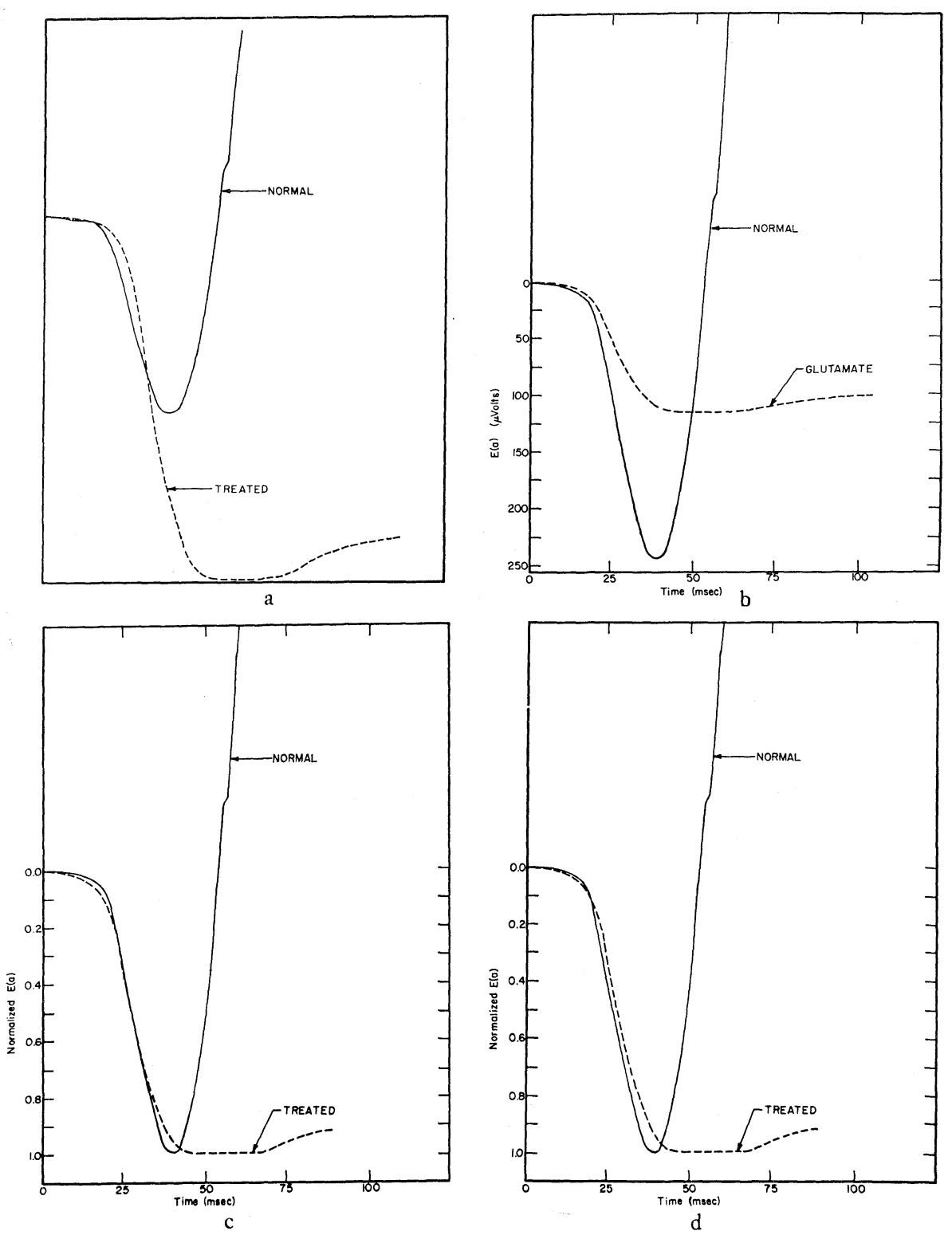

FIG. 11. Comparison of glutamate treated and untreated rat a-waves obtained in response to the same stimulus. (a) Tracings of enlarged a-waves. The amplifications of the a-waves are different. The voltage calibration for each a-wave is given. (b) a-waves corrected for different amplifications and plotted vs. time. (c) Normalized a-waves plotted vs. time. The a-waves were positioned so that their slopes were superimposed. (d) Normalized a-waves plotted vs. time. The a-waves were positioned so that their latencies were superimposed. To obtain the normalized a-waves, every point in each a-wave in (b) was divided by its maximum amplitude. 
were superimposed. The normalized a-waves obtained from the untreated rat and the glutamate treated rats are similar. The peak latency of the awave obtained from the untreated rat appears earlier. This is to be expected, since there is little b-wave in the glutamate treated rat, and since the a-wave peak latency represents the point at which the rates of the generation of the a-wave and $b$-wave are equal, as BUCKSER ${ }^{11)}$ proposed.

These experiments were done while the author was on staff of the Eye Research Laboratories of the University of Chicago. The author is grateful to Dr. A. M. PotTs for his support and advice. He also wishes to thank Mr. Kenneth Peters for his technical assistance.

This work was supported in part by Public Health Service Research Grant No. NB-02522 from the National Institute of Neurological Diseases and Blindness.

\section{REFERENCES}

1) Lucas, D. R. and Newhouse, J. P.: The Toxic Effect of Sodium 1-Glutamate on the Inner Layers of the Retina. A. M. A. Arch. Ophth., $58: 199-201,1957$.

2) Potts, A. M., Modrell, R.W. and Kingsbury, C.: Permanent Fractionation of the Electroretinogram by Sodium Glutamate. Amer. J. Gphth., $50: 900-905,1960$.

3) Potrs, A. M.: Selective Action of Chemical Agents on Individual Retinal Layers, in The Biochemistry of the Retina, pp. 155-162, edited by C. Graymore, Academic Press, London, 1965.

4) Cone, R.A.: Ouantum Relations of the Rat FRG. J. Gen. Physiol., 46:12671281, 1965.

5) Dowling, J.E.: Science, $157: 584-585,1967$.

6) Buckser, S.: Sub-wave Nature of the Albino Rat Electroretinogram. Curr. in Med. Biol., 1: 259-274, 1967b.

7) Buckser, S.: Spectral Analysis of the Albino Rat Electroretinogram. Curr. in Mod. Biol., 2 : 14-20, 1968a.

8) Buckser, S.: Electromagnetic Shutter Suitable for Electroretinography. Rev. Sci. Instruc., $37:$ 422-425, 1966.

9) Buckser, S.: Recovery of the Albino Rat Electroretinogram After Partial Light Adaptation. Photochem. and Photobiol., $6: 73-82,1967 \mathrm{a}$.

10) Buckser, S. and Potts, A. M.: Studies on the A-wave I. The A-wave During Dark Adaptation. Clinical Electroretinography, Proc. of ISCERG Conf. of 1964. Pergammon Press, 177-185, 1966.

11) Buckser, S.: Fine Structure of the Frog Electroretinogrm. Comp. Biocnem. and Physiol., $25: 65-80,1968 \mathrm{c}$

12) ARden, G. B. and BRown, K. T.: Some Properties of the Cat Electroretinogram Revealed by Local Recording Under Oil. J. Physiol., 176: 429-461, 1965.

13) Buckser, S.: Some Properties of the Electroretinogram Long Latency Negative Wave Obtained Below the B-wave Threshold. Comp. Biochem. and Physiol., 24: 487-502, 1968b.

14) Buckser, S.: Studies on the ERG II. Model of an A-wave Regenerator Mechanism. Bull. Math. Biophys., $27: 223-233,1965$.

15) Hubbard, R., Bownds, D., and Yoshizawa, T.: The Chemistry of Visual Photoreception. Cold Springs Harbor Symposium, Vol. XXX, 301-315, 1965. 